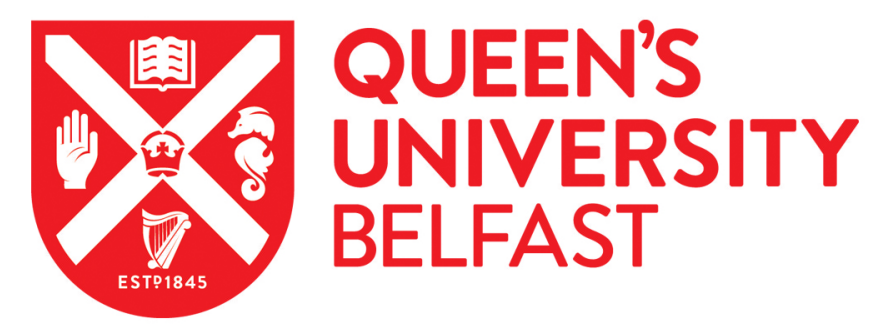

\title{
Modelling and Control of a 96V Hybrid Urban Bus
}

Murtagh, M., Early, J., Stevens, G., Cunningham, G., Douglas, R., \& Best, R. (2019). Modelling and Control of a 96V Hybrid Urban Bus. In WCX SAE World Congress Experience 2019: Proceedings (SAE Technical Papers).

SAE International. https://doi.org/10.4271/2019-01-0354

Published in:

WCX SAE World Congress Experience 2019: Proceedings

Document Version:

Peer reviewed version

Queen's University Belfast - Research Portal:

Link to publication record in Queen's University Belfast Research Portal

Publisher rights

(C) 2019 SAE.

This work is made available online in accordance with the publisher's policies. Please refer to any applicable terms of use of the publisher

\section{General rights}

Copyright for the publications made accessible via the Queen's University Belfast Research Portal is retained by the author(s) and / or other copyright owners and it is a condition of accessing these publications that users recognise and abide by the legal requirements associated with these rights.

Take down policy

The Research Portal is Queen's institutional repository that provides access to Queen's research output. Every effort has been made to ensure that content in the Research Portal does not infringe any person's rights, or applicable UK laws. If you discover content in the Research Portal that you believe breaches copyright or violates any law, please contact openaccess@qub.ac.uk. 


\title{
Modelling and Control of a Hybrid Urban Bus
}

\author{
Author, co-author (Do NOT enter this information. It will be pulled from participant tab in \\ MyTechZone) \\ Affiliation (Do NOT enter this information. It will be pulled from participant tab in MyTechZone)
}

\begin{abstract}
This paper describes the development and on-vehicle validation testing of next generation parallel hybrid electric powertrain technology for use in urban buses. A forward-facing

MATLAB/Simulink powertrain model was used to develop a rulebased deterministic control system for a post-transmission parallel hybrid urban bus. The control strategy targeted areas where conventional powertrains are typically less efficient, focused on improving fuel economy and emissions without boosting vehicle performance. Stored electrical energy is deployed to assist the IC engine system leading to an overall reduction in fuel consumption while maintaining vehicle performance at a level comparable with baseline conventional IC engine operation. Regenerative braking is integrated with the existing braking systems on the vehicle, and the control system tailored to maximise the amount of energy recuperated during deceleration events and accelerator pedal lift off without adversely impacting on the normal behaviour of the vehicle. The control system was implemented on both prototype single (Streetlite) and double-deck (Streetdeck) vehicle configurations for real vehicle testing with partner Wrightbus. The hybridisation has reduced equivalent $\mathrm{CO}_{2}$ emissions by $34 \%$ (single-deck)/ $35 \%$ (double-deck) over the conventional Euro VI diesel vehicle on the Low Carbon Vehicle Partnership UK bus cycle (based on London Bus Route 159). These results compare favourably with alternative powertrain technologies currently available with similar certification. Moreover, the next generation hybrid urban bus has several distinct advantages as it is less restricted by infrastructure, range, or terrain issues, and has a comparatively lower purchase price point. Hybrid bus technologies offer the option of maintaining existing service levels without significant modifications to operations or budgets while achieving significant reductions in average fleet emissions.
\end{abstract}

\section{Introduction/Overview}

With demand for increasingly fuel-efficient vehicles growing, largely driven by ambitious targets to reduce (or eliminate) tailpipe emissions, there has been a surge in hybrid-electric and electric technology development within the automotive industry. Similar drivers within the bus industry have seen many of the same technologies entering into service. The earliest hybrid technologies relied on smart ancillary or 'micro' hybridisation of existing diesel powertrains, introducing combinations of start-stop technology and transferral of auxiliary systems to electric power sources, alongside schemes targeted at minimisation of weight. Later moves towards full hybridisation have resulted in a number of successful full series and parallel hybrid urban bus vehicles going into service globally. However, challenges with balancing achievable emission and fuel consumption reductions against increased total cost of ownership still remain. Estimates of total cost of ownership per $\$ / \mathrm{km}$ range from $2.85 \$ / \mathrm{km}$ to $2.98 \$ / \mathrm{km}$ for full hybrid vehicles, compared against $2.61 \$ / \mathrm{km}$ for an equivalent diesel vehicle [1]. This is largely due to the high purchase price point of the vehicle, with purchase cost (on average) $45 \%$ (parallel powertrain) to $59 \%$ (series powertrain) higher than an equivalent diesel vehicle [1].

While fully electric bus architectures are emerging into the global marketplace, hybrid technologies are likely to still be prominent in the bus sector through to 2035 (and potentially beyond) [2] as component weights, achievable ranges, lower component availability, reliability, cost, aggressive and varied duty cycles in the bus sector all continue to present barriers to mass adoption of fully electric technologies. To mitigate the increased cost of the full hybrid powertrain, alternative hybrid powertrain topologies could provide a cost-effective alternative within the bus industry. Improved integration of motor generator units (MGUs) into the powertrain can allow for quick firing of the engine, providing additional torque to improve fuel consumption performance during full load acceleration events and, in some configurations, transmitting torque pulses to the engine to reduce vibration. These power assist strategies can be particularly attractive for urban style driving cycles, as is typically encountered within bus operation.

The current work presents a $96 \mathrm{~V}$ parallel-hybrid bus control strategy which has been developed and implemented on both single and double deck next generation hybrid bus topologies. The system has been proven to deliver $\mathrm{CO}_{2} \mathrm{e}$ Well-to-Wheel emissions savings of up to $35 \%$ over an equivalent Euro VI configuration through vehicle testing and has been certified in the UK as a Low Emission Bus. The paper will first present the forward-facing modelling strategy which was developed to support the preliminary sizing of components in the vehicle architecture and testing of the initial rule based deterministic control strategy, before presenting the vehicle testing and certification results.

\section{Background to Hybridisation in the Bus Industry}

Local emissions legislation has had a significant impact on the technology choices within the bus sector, driven by the phased introduction of low and ultra-low emissions zones in many towns and cities $[3,4]$. These new zones have long term impact on the continued viability of many of the more traditional diesel-based bus architectures, particularly as regulations become increasingly more stringent. Various solutions including low-emission diesel, hybridisation, full electrification and alternative fuels have emerged but there are still outstanding issues with cost of acquisition, 
infrastructure availability and the balance between solutions which are appropriate for servicing both urban and semi-urban/rural operations.

While fully electric configurations are gaining prevalence in some markets [5], the technology is still relatively immature, and the UK Automotive Council roadmaps highlight the continuing need for hybrid technologies within the bus sector through to 2035 [2]. This mirrors the status in many other countries globally. These hybrid vehicles can be largely categorised into 'micro-hybrid', where electric ancillary systems have been included in the powertrain to reduce fuel consumption, such as smart alternators, stop-start systems and electric compressors, 'full-hybrid', where the traction power for the system can be fully derived from an electric

MGU/inverter/battery system either in a series, parallel or power-split configuration, and 'mild-hybrid', where the electrical system assists the primary IC engine based propulsion system to reduce overall fuel consumption (but is not typically capable of providing electric propulsion as a standalone system). In the current work, a latest hybrid bus topology is proposed which blurs the lines between the categorisation of micro, mild and full hybrid technologies as it is built upon a micro-hybrid platform and integrates a hybrid traction system, but has the capability to power the vehicle with the IC engine switched off for short periods which would make the system more closely aligned with a full hybrid powertrain. For clarity, the vehicle developed here is described as a hybrid bus as it merges all three types of hybrid configuration into a single architecture.

This configuration is a particularly interesting solution as a 'bridging' technology, offering opportunities for significant improvement of the fuel economy of the vehicle while meeting the short to medium term emissions legislation for low emission bus operation at lower cost of acquisition. It is in this context that the ambition in the current programme of work was to develop a new parallel-hybrid configuration which builds upon an existing successful third generation of micro-hybrid vehicle powertrain, the Wrightbus Micro Hybrid v3 (MHv3) to develop a next generation hybrid bus vehicle (designated as HEV). The baseline MHv3 vehicle employs smart alternators, electric power assisted steering (EPAS), electric air compressor for the pneumatic suspension, brakes and door systems, and stop-start engine technology to maximise efficiency of the twin turbocharged 5.1 litre Euro VI certified Daimler engine. The baseline $24 \mathrm{~V}$ system is retained for lower cost ancillaries, reducing the expense associated with integrating these into the higher voltage system. A similar approach has been adopted in the current vehicle development work with the smart alternators, electric air compressor and engine start-start retained on a private $24 \mathrm{~V}$ network.

However, despite being built upon an existing vehicle topology, the development of the configuration is not without its challenges. Firstly, the power demands in the commercial sector are significantly higher than those encountered in the wider automotive sector, in which $48 \mathrm{~V}$ architecture has become popular for many of the emerging mild-hybrid and hybrid configurations [6]. There are several configurations, categorised by the location of the MGU in the powertrain, that can be adopted, ranging from $\mathrm{P} 0$ which incorporates a belt driven starter and generator through to $\mathrm{P} 4$ with the MGU located on the drive axle. During development of the current vehicle architecture, an initial P0/P1 style hybrid with an engine mounted MGU on a $48 \mathrm{~V}$ system was considered, as this is the most straightforward configuration to implement and is one of the most popular configurations for emerging vehicles [6]. However, for this particular powertrain, it was found to have limited fuel consumption reduction benefits when balanced against the increased cost of the vehicle with the new electrified components.
The P2 location was briefly considered, however, this location had the same issues with efficiency improvements as the P0 and P1 positions. This will be demonstrated later in the management of power flow section.

In subsequent design iterations, the MGUs were relocated to the P3 position (the output of the transmission) to reduce efficiency losses in the transmission and maximise the energy recovery, while improving packaging within the engine bay. However, a clear opportunity to increase the system voltage was identified to meet the power and torque required/available at this position in the drivetrain.

Moving to a 96V system, as proposed here, doubles the electrical power available to be captured/deployed when the same maximum current limitations are applied. However, the options for 'off the shelf' components are limited in this voltage range, which can add a price premium to many of the powertrain elements which was balanced against the losses incurred in the lower voltage systems.

Once component sizing is determined, the management of the interdependency between two power sources needs to be addressed. The energy management strategy must deliver seamless operation while taking full advantage of the electric system for fuel/emissions reduction. However, as there are two simultaneous power flows in the system, unlike that encountered in a series hybrid, fully electric or conventional diesel vehicle, the blend must be managed carefully to reduce impact on the drivability of the vehicle. Typical considerations in the development of the power management strategy include:

- How to effectively manage the power distribution between the power sources to maximum efficiency and seamlessly blend the power supplies to provide uninterrupted torque;

- How to identify and maximise the energy recovery and regenerative opportunities for the vehicle while complying with legislative requirements for braking;

- How to minimise the impacts of the new powertrain on the driveability and transition between system states.

Numerous power management strategies have been developed over the years in support of vehicle development activities, largely classified as rule-based or optimisation-based strategies [7, 8, 9]. While optimisation-based methods have significant advantages over the rule-based deterministic and fuzzy-logic based approaches, they also require significantly more understanding of the full scope of potential behaviours of the vehicle and can therefore introduce challenges when applied to real-time control problems where it is not necessarily possible to have a priori knowledge of the driving conditions. Fuzzy logic-based approaches (both traditional and adaptive) have been shown to have benefits for fuel consumption improvements in simulation-based environments with improved vehicle power demand handling [8], but there are, to date, limited examples of these techniques being successfully implemented within real hybrid electric vehicle powertrain control systems. For this reason, a rule-based $(\mathrm{RB})$ deterministic control strategy was adopted for the development of the control strategy in this work, where a set of 'if-then' rules are determined to identify the appropriate/viable response to a given set of inputs (Figure 1). 


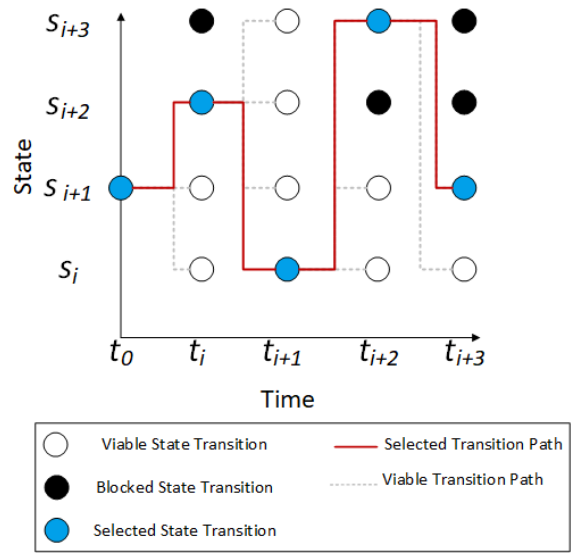

Figure 1. Deterministic state transitions

While this will not necessarily identify the 'optimal' control pathway, it does significantly reduce the risk in the control system implementation. This was determined appropriate for both the development of the preliminary Simulink modelling environment, and the later implementation on the prototype vehicles. However, while a more straightforward approach than many comparative optimisation-based methods, there is still significant challenges in implementing a RB algorithm as it typically relies heavily on user expertise and system knowledge and is further complicated by the many non-linear behaviours displayed by the powertrain components, such as the battery and engine components.

Due to the complexity of the underlying control strategy, a forwardfacing vehicle model of the proposed $96 \mathrm{~V}$ parallel-hybrid single (Streetlite) and double deck (Streetdeck) vehicles were first developed within the MATLAB/Simulink modelling environment and used to develop the first-generation control strategy concept for the new parallel-hybrid concept (designated as Streetlite HEV and Streetdeck HEV). One of the targets was to develop a representative scalable control strategy which would offer significant savings for both vehicle configurations without significant redevelopment required. Forward facing vehicle models which could accurately capture the temporal powertrain behaviours were developed to fully explore the range of behaviours and interdependencies between system components and their overall impact on the desired vehicle performance. Once established, the baseline vehicle models were validated with data from a series of prototype vehicle tests at the Millbrook Proving Ground in Bedford, England.

The following sections will provide an overview of the modelling strategy which was adopted for provisional analysis of the next generation parallel-hybrid vehicle architecture, highlighting the main challenges encountered in developing an efficient control strategy, before introducing the certification testing which has ultimately resulted in both vehicles meeting limits for certification as Low Emissions Buses in the UK.

\section{Modelling of the Electro-mechanical Powertrain Architecture}

As a first step, a forward-facing model of the configuration was developed within Simulink. The modelling approach adopted in this work is based on a forward-facing logic, follows the approach presented by Stevens et al. [10]. The vehicle development programme was built around a desire to retain the baseline microhybrid (Wrightbus MHv3) system, while integrating the new

Page 3 of 11 electrical components into the existing powertrain. This new powertrain consists of a twin turbocharged 5.1 litre Euro VI certified Daimler unit, a four-speed transmission, two Schaubmüller MGUs, two Schwarzmüller inverters and a Microvast 96V lithium ion battery pack.

A schematic of the hybridised powertrain is shown in Figure 2, indicating the primary components in a post-transmission $(\mathrm{P} 3)$ parallel configuration. A driver model provides the necessary engine torque and braking demand to follow the prescribed drive cycle as inputs to the simulation (Figure 3). This type of dynamic causal modelling approach captures the instantaneous changes of state of the vehicle components, allowing the effectiveness of the control strategy to be assessed, but does significantly increase the complexity and computational expense of the vehicle model relative to alternative non-causal kinematic (backwards facing) models which are traditionally used for early stage component sizing studies.

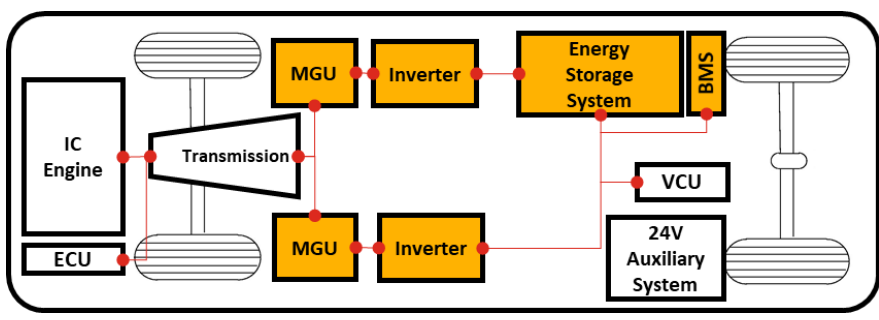

Figure 2. Schematic of Parallel-Hybrid Driveline Components

The choice of the forward-facing approach was driven by the need to develop detailed understanding temporal dynamics of the two power flows in the powertrain (IC Engine and MGUs) for development and testing of an appropriate control logic.

The battery was modelled as a single cell model scaled to the same capacity as the full pack, developed from the coulomb counting methodology such that $\operatorname{SOC}(t)=\operatorname{SOC}\left(t_{0}\right)+\frac{1}{C} \int_{t_{0}}^{t} i d t$ where $\operatorname{SOC}(t)$ is the state of charge at time t, expressed as a percentage, $S O C\left(t_{0}\right)$ is the state of charge at the initialisation of the simulation when $t=0$ also expressed as a percentage, $C$ is the capacity of the battery measured in amp.s (amp-seconds) or coulombs, C, and $I$ is the instantaneous current in amps. The usage battery range for the simulations was defined as 30-70\%. Engine, MGU and inverter efficiency maps were developed through a series of dynamometer tests which characterised integrated performance across a range of testing conditions. Models of each system component (engine, MGUs, inverters, battery) were developed, tested and validated in isolation prior to coupling in the final powertrain configuration.

One objective of the control strategy was ultimately to distribute the torque demand between the IC engine and the MGUs to provide the necessary tractive force at any point during a prescribed set of driving events. In order to do this, the underlying energy management strategy was required to:

1. Distribute the required torque demand between the engine and MGU systems to maintain high overall system efficiency;

2. Manage a charge sustaining strategy that complies with the testing requirements and maintains the SOC within stated capacity limits and prevents rapid charge/discharge events;

3. To smoothly transition between system operational states during acceleration events;

4. To smoothly transition between system operational states during braking events; 
This largely divides the power management strategy into two key problem areas: Power Delivery for Driving Events and Energy Storage Management.

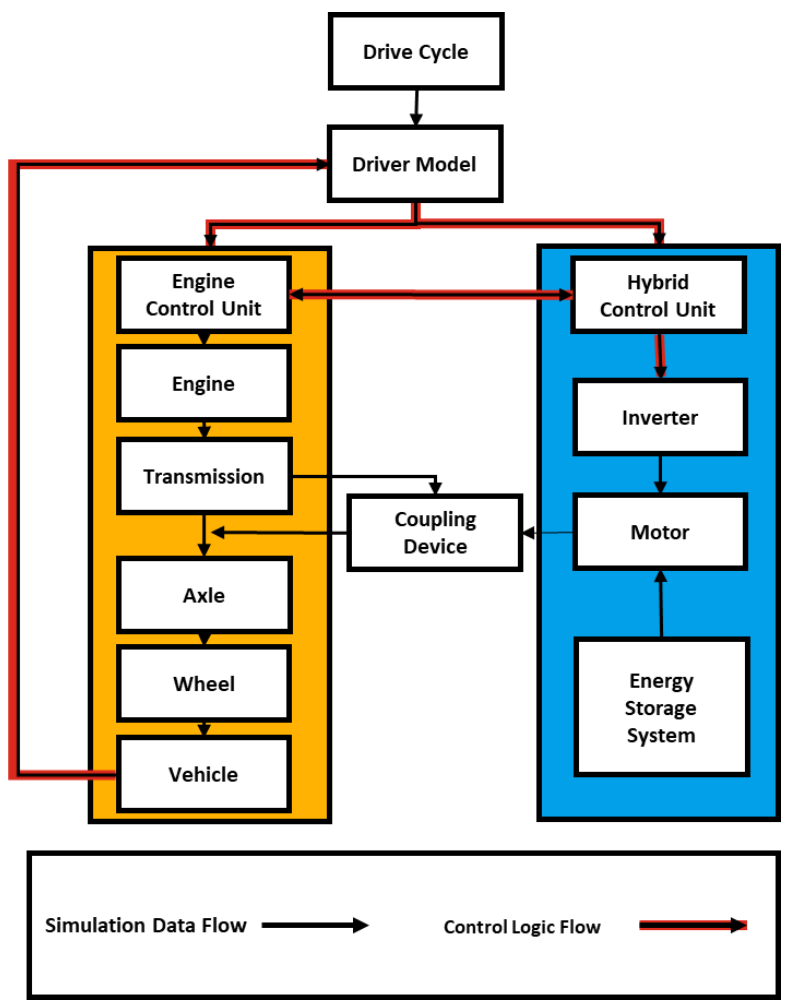

Figure 3. Forward facing control logic

The first input into the system is the upfront total torque demand from the system in real-time. For the Simulink modelling activity, this was supplied through a PID controller which emulated the driverin-the-loop. A 'look ahead' function was built into the model which allowed the driver to 'see' the next several seconds of the drive cycle and produce a more stable model output, and to be more representative of the real world where a driver has visual cues and has advanced warning of upcoming bus stops, road junctions, etc. The Low Carbon Vehicle Partnership UK Bus Cycle (LUB) drive cycle was used to guide the driving simulation through a logical sequence of driving events which replicate the bus emissions test profile in the UK (Figure 4) [11]. The cycle replicates a range of different driving styles (urban, sub-urban and rural), enabling realistic evaluation of bus performance across a range of different driving characteristics (Table 2).

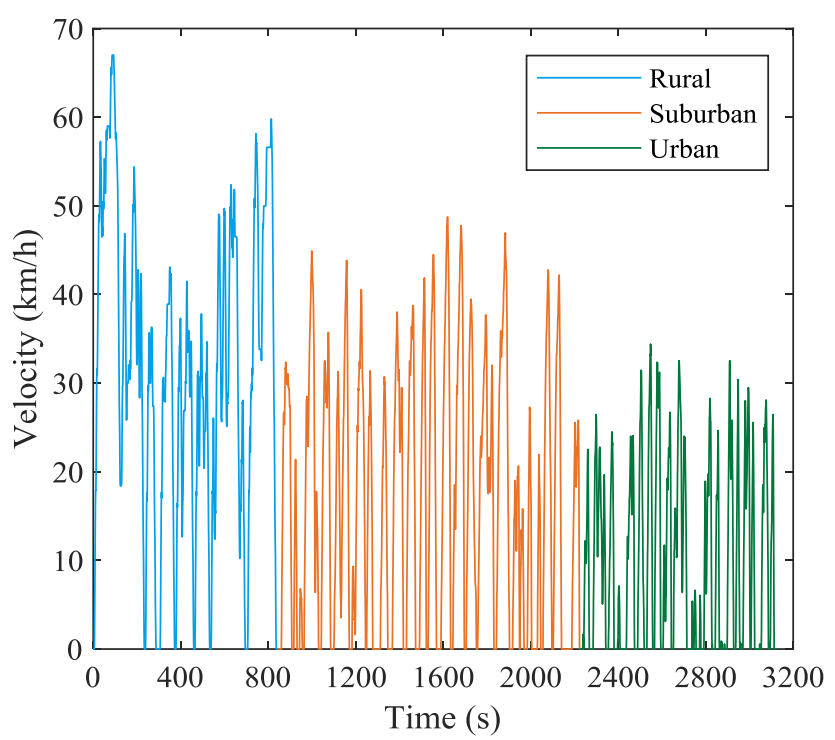

Figure 4. Low Carbon Vehicle Partnership UK Bus Cycle [11]

Table 2. Drive Cycle Configuration [derived from 8]

\begin{tabular}{lcc}
\hline & $\begin{array}{c}\text { Average Speed } \\
(\mathbf{k m} / \mathbf{h})\end{array}$ & $\begin{array}{c}\text { Distance } \\
(\mathbf{k m})\end{array}$ \\
\hline Rural & 31.51 & 7.40 \\
\hline Suburban & 16.85 & 6.47 \\
\hline Urban & 10.02 & 2.50 \\
\hline Total & 18.85 & 16.37 \\
\hline
\end{tabular}

Two vehicle configurations, one based on the Wrightbus Streetlite HEV single deck configuration, the second on the Wrightbus Streetdeck HEV double deck configuration, have been used to demonstrate the scalability of the powertrain to different vehicle types and loadings with limited modification to the control logic implemented. For clarity in presentation, only the simulation results relating to the double deck Streetdeck variant will be discussed.

\section{Parallel Hybrid Power Management Strategy}

The power management strategy for the parallel hybrid vehicle is determined through a combination of the driver request and the vehicle state at the point of the request. These states can be classified as follows:

1. Vehicle Idle: Baseline vehicle idle state.

2. ICE only: Logical conditions that results in only engine torque being delivered to the system.

3. Hybrid torque assist: Logical conditions that activates the MGU to provide supplementary power to the vehicle powertrain to assist propulsion of the vehicle (for instance, during full load acceleration events).

4. Hybrid regenerative torque: Braking events that enable recharging of the battery to occur, based on vehicle speed, driver braking requests and SOC of the battery.

The logical sequence of messages between the driver, HCU controller, engine, MGUs and battery are shown in Figure 5: 


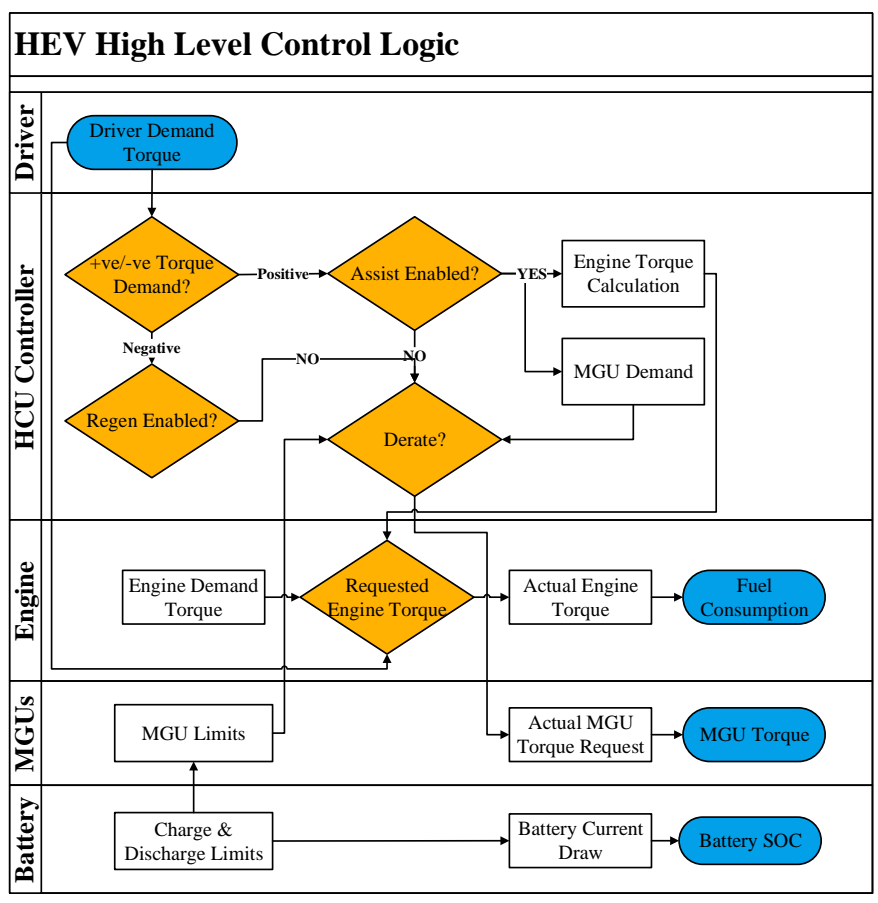

Figure 5. HEV High Level Control Logic

Alongside the need to provide smooth and continuous blending of the power flow from both the IC engine and MGU is the need to ensure that the various braking systems are also smoothly integrated on the vehicle. Requirements to manage the distribution of braking force in the vehicle raises particular challenges in ensuring that the system is not only capable of recovering as much braking energy as possible, but to do so while complying with the relevant directives and legislation, which in the EU are covered by EU 96/53/EEC; 2002/7/EC; 97/27/EC; 2003/19/EC; 71/320/EEC; 2002/78/EC; ECE regulation 13 and 2001/85/EC/ECE Regulation 107. For all buses, it is a mandatory requirement that the vehicle is fitted with foundation brakes, and a retarder fitted to comply with downhill behavioural tests. With three systems providing effective braking force to the vehicle, careful implementation of control logic is required to blend the different systems to create a smooth and safe braking experience for the driver and passengers.

The initial braking system implemented within the Simulink environment was based upon balancing the total requested braking torque across the three systems as a function of the maximum torque available from the MGUs at any given point of time as a function of the current vehicle state, shown in Figure 6.

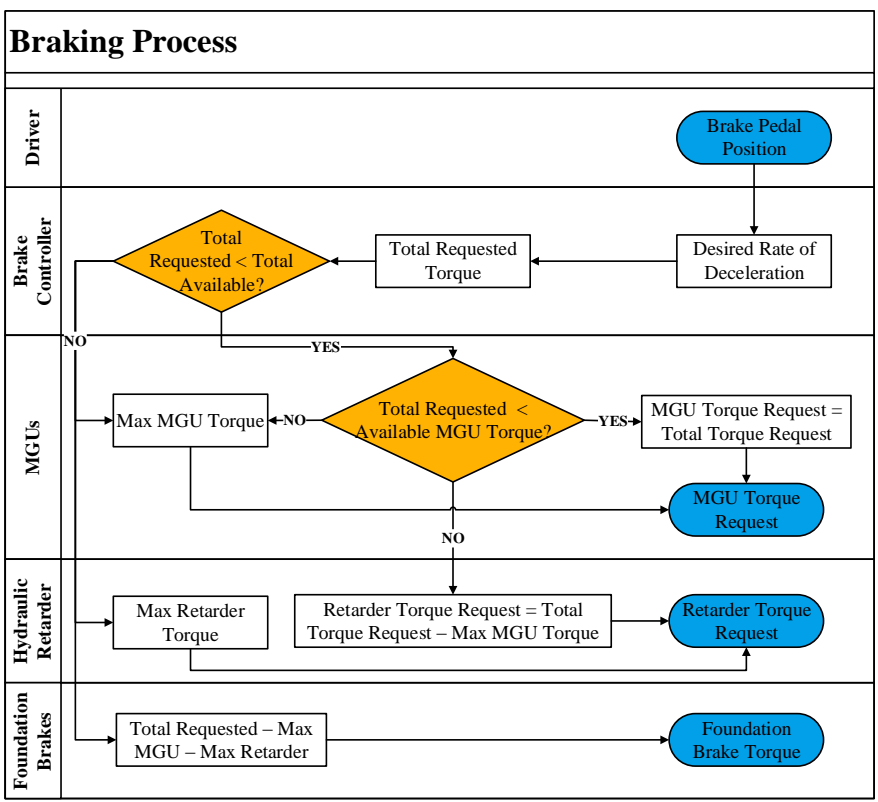

Figure 6 - Flow Diagram of HEV Braking Process Decision Tree

\section{Management of power flow between power sources - Simulink Modelling}

The objective for the power flow management on the vehicle was to reduce fuel consumption (and therefore emissions) while maintaining comparative driving performance of the baseline micro-hybrid vehicle. In order to achieve this, the driver's demand torque is split between the engine and MGUs such that the maximum MGU torque available at each time instance is deployed, subject to the battery SOC and the battery discharge limits, with the remaining torque requested of the engine.

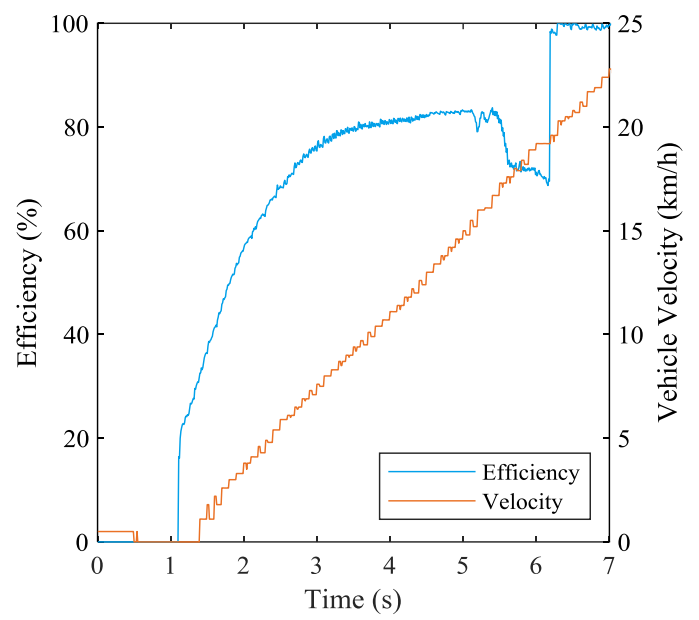

Figure 7 - Transmission efficiency during acceleration (MH v3)

Figure 7 shows one of the key areas targeted by the control strategy, which is the management of the overall powertrain efficiency at low vehicle speeds. On this vehicle, the transmission efficiency has a large effect on the overall efficiency. Therefore, the assist torque from the MGUs is deployed during the periods where the transmission efficiency is low. This is typically at vehicle speeds lower than $20 \mathrm{~km} / \mathrm{h}$. 


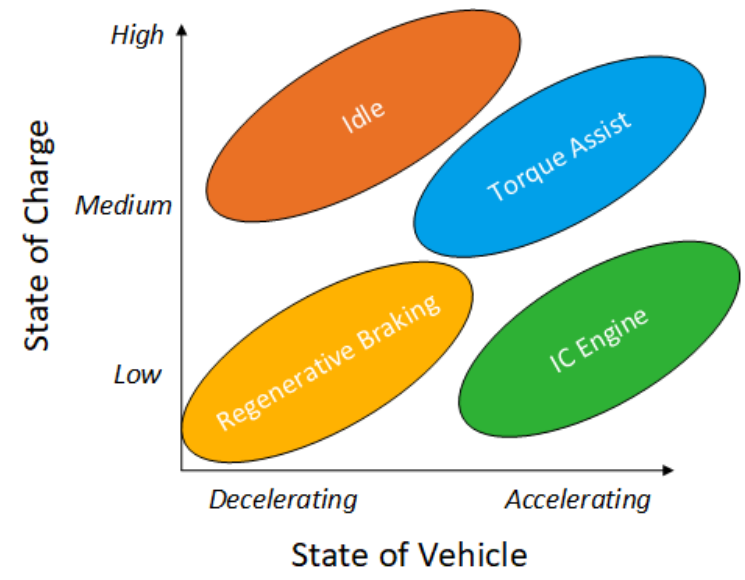

Figure 8-Schematic of Power Flow Management as a function of SOC and State of the Vehicle

To replicate real world behaviour, the driver demand torque in the vehicle model is calibrated to account for physical limitations of the engine due to dynamic processes such as the build-up of turbocharger boost pressure or other systems on the engine limiting the torque output, for example, to control smoke or the idle governors.

When a positive torque request is received by the model, the amount of torque demanded from the MGU is determined as a function of the torque demand, the SOC of the battery, the vehicle speed and the current gear ratio. The model has been tuned so that when the SOC is high, the MGU will assist for a longer period of time proportional to the SOC. Conversely, when the SOC approaches its lower threshold limit, it reduces the assistance period to compensate. These charge sustaining measures ensure that the SOC of the battery is effectively marshalled towards a nominal SOC value throughout the drive cycle.

Once implemented, the first check is that to ensure that the vehicle can replicate the desired acceleration and deceleration profiles and the energy management strategy has not adversely affected the delivery of torque in each time instance. Figure 9 shows a representative acceleration/deceleration event during the LUB cycle from the Streetdeck HEV vehicle model. The Simulink HEV model is benchmarked against the existing micro-hybrid (MHv3) vehicle model, which has previously been fully validated for this drive cycle. The actual engine torque (as a percentage of the maximum torque available during the simulation) delivered by the micro-hybrid and parallel hybrid variants of the vehicle during simulation are shown during the same acceleration and deceleration events in Figure 10. From the vehicle acceleration profiles, there is no clear degradation in vehicle performance from the management strategy which has been implemented with both vehicles achieving comparable acceleration and deceleration performance.

At 998 seconds, the effect of torque assist from the MGUs can be seen in Figure 10, at which point there is a clear reduction in the engine torque provided by the Streetdeck HEV relative to the engine torque provided by the micro-hybrid vehicle in the same time frame to provide the same acceleration performance. This reduction in torque persists to approximately 1025 seconds, at which point the vehicle starts to decelerate.

Figure 11 shows the engine torque provided by the engine and MGU for the HEV vehicle during the simulation in this same time instance. The assist during the acceleration phase (red trace) is evident, followed by a regenerative event (indicated by the negative MGU

Page 6 of 11 torque applied). Overall, the strategy is effective at reducing the peak torque demands at low engine speeds, therefore reducing instantaneous fuel consumption peaks, to improving overall efficiency characteristics. Figure 12 shows the low engine speed range for both MHv3 and $\mathrm{HEV}$ vehicles overlaid, with a significant reduction in instances of high torque demands for the HEV relative to the MHv3 configuration for the same drive cycle.

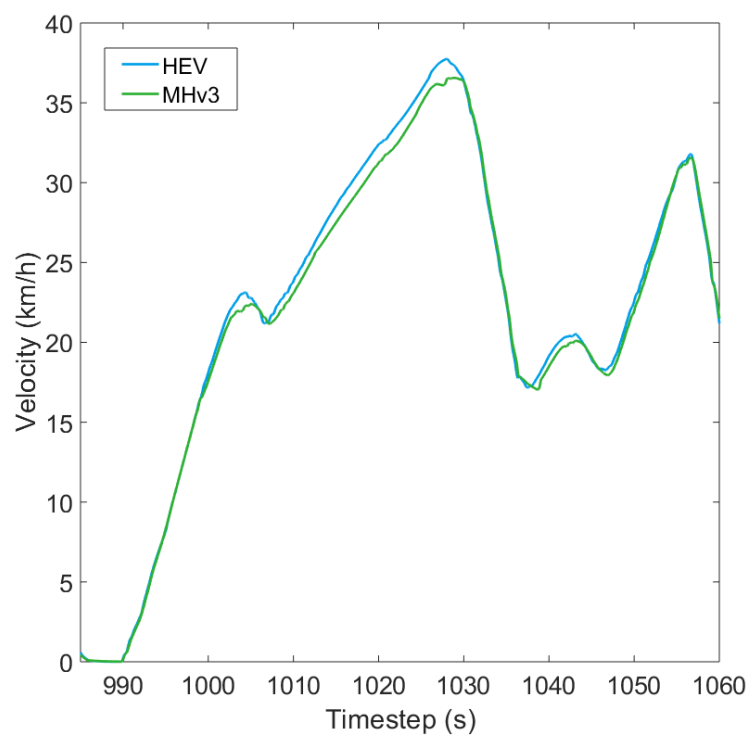

Figure 9. Simulated vehicle velocity profile response

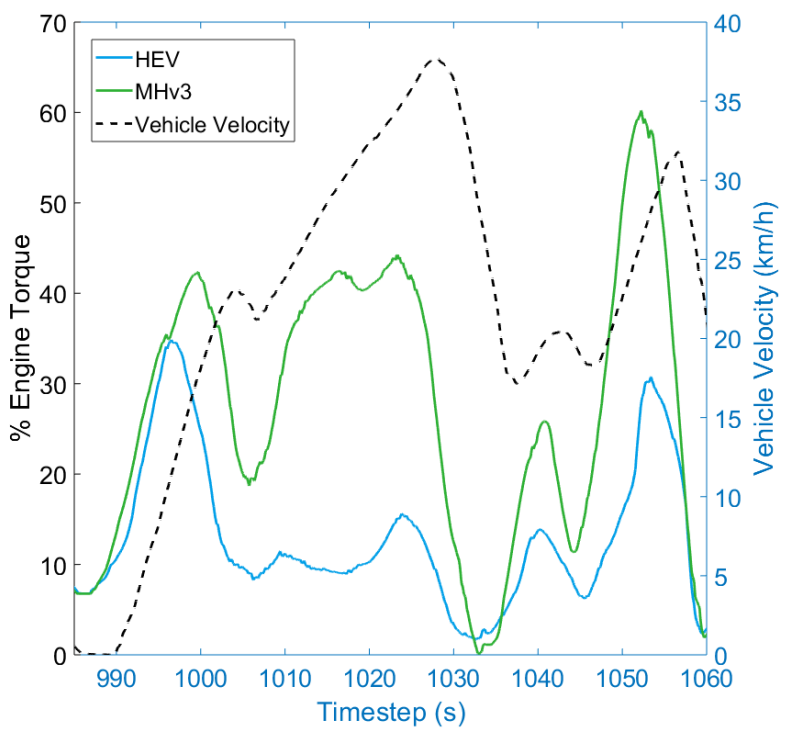

Figure 10. Actual Engine Torque for MHv3 and HEV cases for the same driving profile

For negative torque requests (deceleration events), the requests are handled in a similar fashion based on the current operational state of the vehicle. Simulation of accelerator pedal lift-off regenerative braking or 'lift-off regen' is achieved in the Simulink model by applying a small regen torque demand. During driver-initiated braking events (where the brake pedal is applied), the amount of regen torque demanded increases as a function of the driver model brake pedal position up to a maximum of $100 \%$. Again, similar to the positive torque requests during assist, if the SOC of the battery is 
high at the point of the negative torque request, the maximum regenerative torque limit is reduced to prevent the SOC exceeding SOC limits of the battery. Conversely, when the battery SOC is low at the point of negative torque request, the maximum regenerative torque limit is set at its maximum and only limited by the amount of regenerative charging events.

Simulations for both vehicles (Streetlite HEV and Streetdeck HEV) confirmed the effectiveness of the assist and regen strategies for both topologies, predicting $10.6 \%$ and $10.5 \%$ reductions in fuel consumption respectively across the LUB cycle during the simulations when benchmarked against the MHv3 technology across the same cycle. The major point of difference between the two vehicle topologies lay in the battery usage across the cycle - for the Streetlite vehicle, the $\triangle \mathrm{SOC}$ from the beginning to the end of the cycle was $-1.2 \%$, whereas the $\Delta \mathrm{SOC}$ for the Streetdeck variant was $3.8 \%$. In both instances the SOC was well within the limits set by the LowCVP. Once the control strategy was verified through the simulations, it was transferred to the test vehicles for further testing and development.

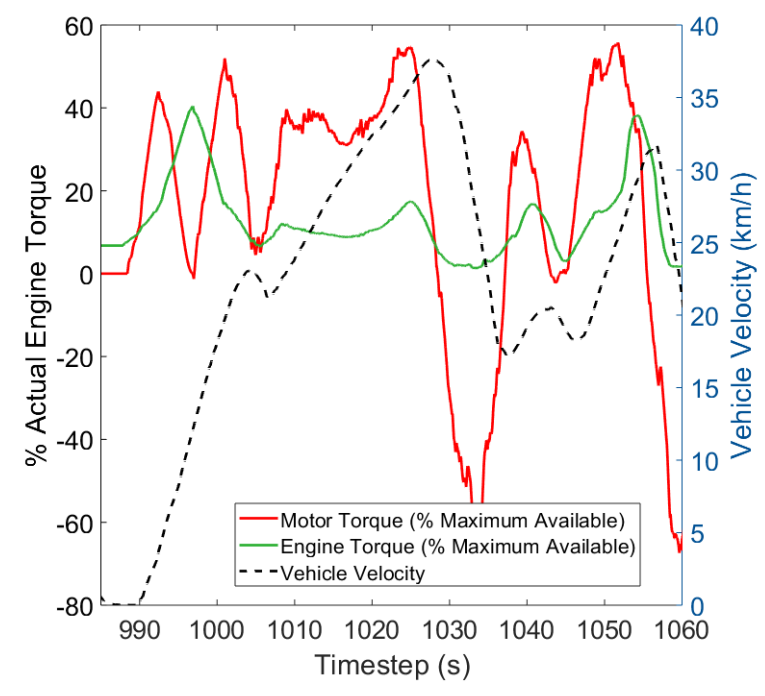

Figure 11. Actual Engine and MGU Torque, showing periods of $M G U$ assist and regen during the driving event

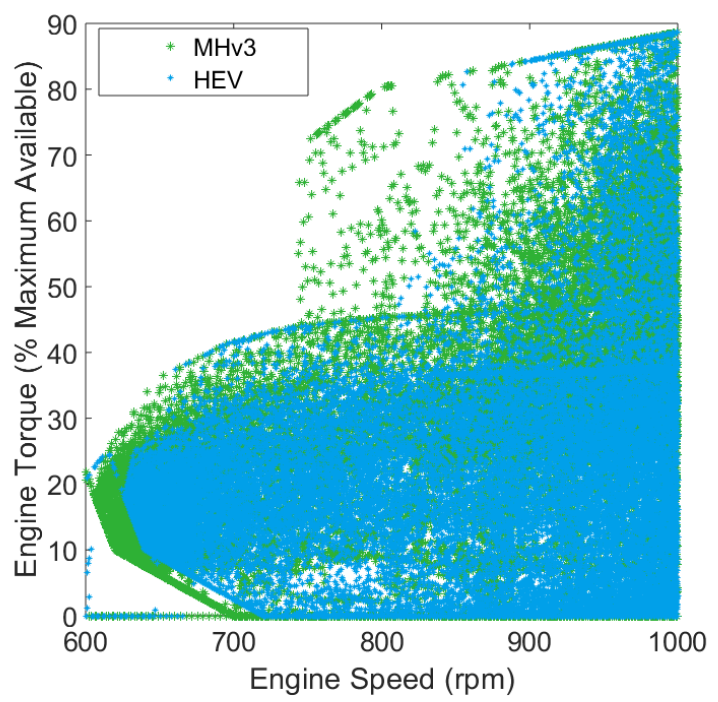

Figure 12. Offset of high engine torque at low engine speeds

\section{Management of power flow between power sources -Vehicle Testing}

The control strategy was implemented on a porotype test vehicle. Checks were undertaken to ensure that comparative acceleration and deceleration performance could be achieved with the hybrid powertrain relative to that of a comparable MHv3 vehicle (Figures 13, 14). Across the actual LUB cycle, the average vehicle velocities were within $0.5 \%$ of each other. Some level of discrepancy would be expected due to variability in drivers during physical testing cycles.

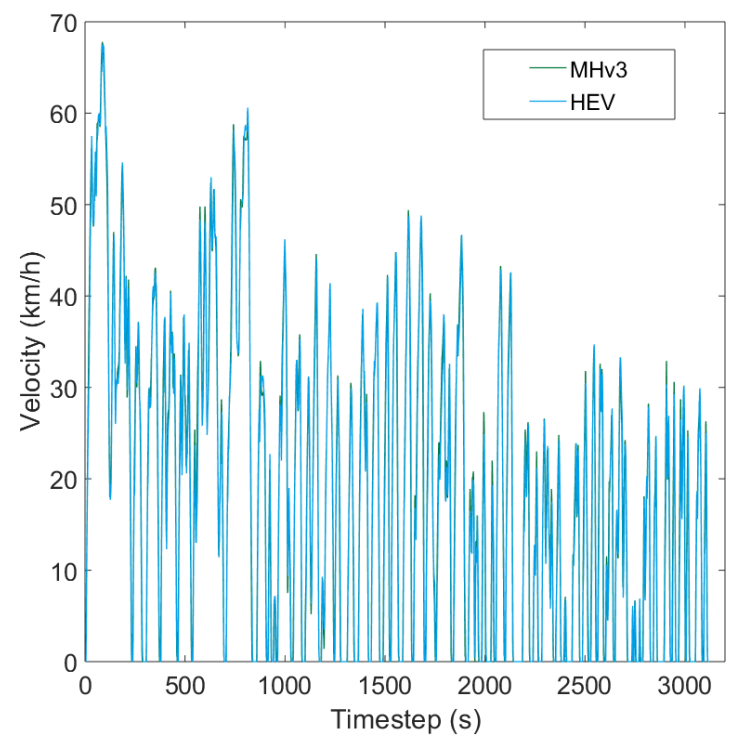

Figure 13 - Vehicle Velocity Profiles for MHv3 and HEV vehicles

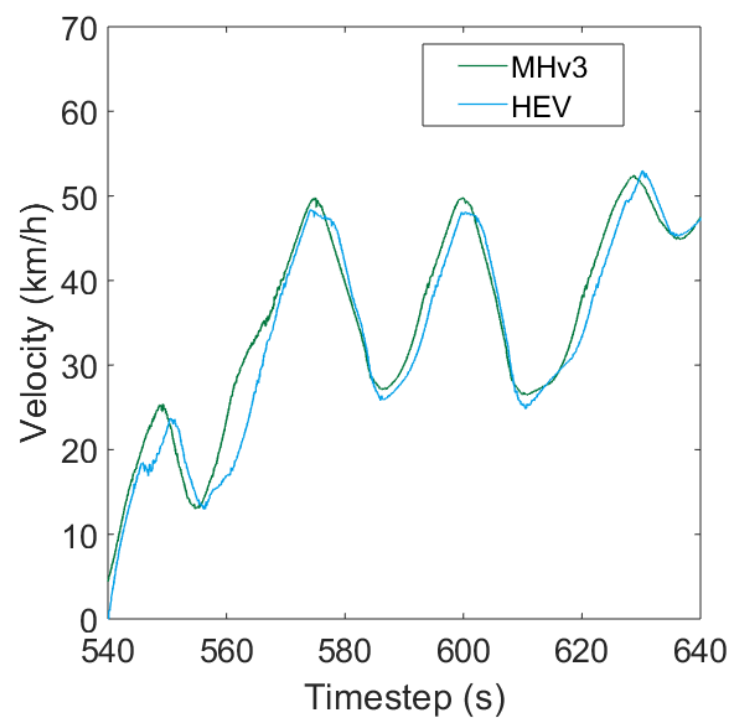

Figure 14 -Velocity Profiles for MHv3 and HEV vehicles (zoomed in)

Figure 15 shows a typical acceleration profile obtained during dynamometer testing on the LUB cycle, again clearly demonstrating that the inclusion of the torque assist feature during acceleration events has not adversely affected the acceleration characteristics of the vehicle.

Page 7 of 11 


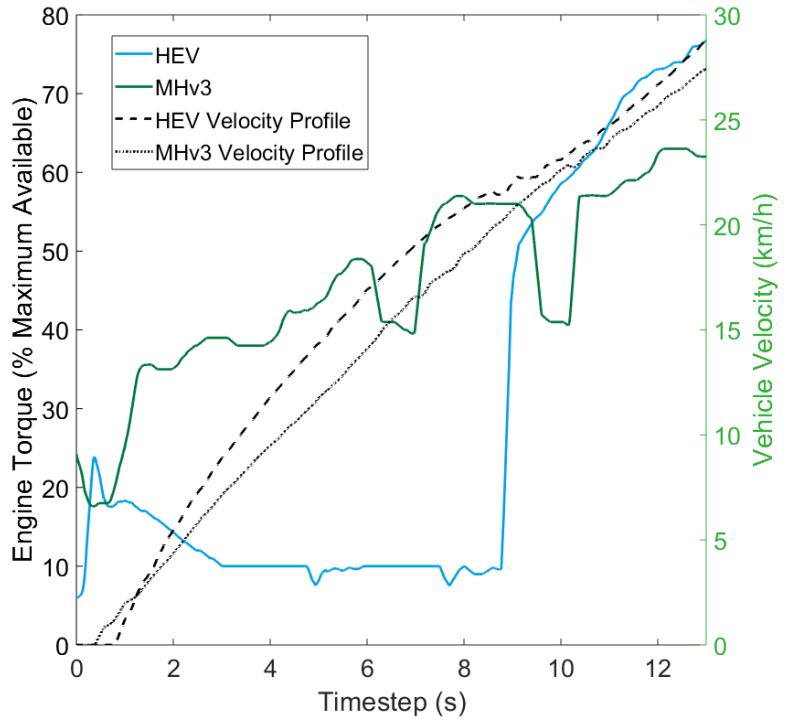

Figure 15 - Corresponding engine torque during previous acceleration

During the acceleration event, the engine torque required during acceleration is substantially reduced. During the first nine seconds of the acceleration event shown in Figure 15, the engine torque is reduced, on average, by $30 \%$ relative to the baseline micro-hybrid vehicle on the same cycle, with the excess torque delivered by the MGUs. This is further reinforced in Figure 16, which shows how the torque demand from the driver is typically distributed between the MGUs and engine, where $100 \%$ of the available MGU torque is utilized (when possible, subject to the SOC and discharge limits of the battery), and the remaining torque delivered from the engine.

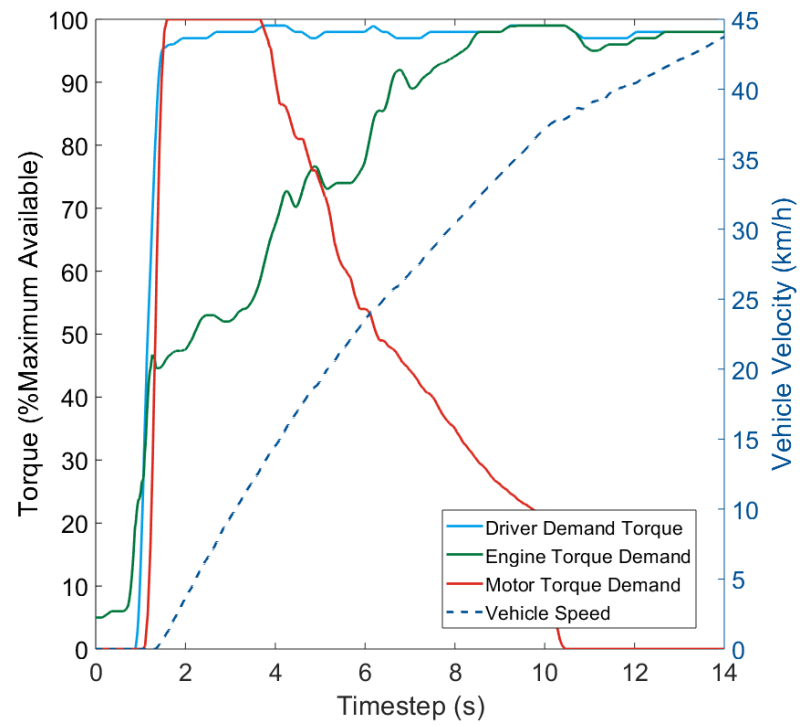

Figure 16 - Engine and MGU torque - HEV only

During the braking events, there are three main braking systems, the foundation brakes, hydraulic retarder and MGUs, which are controlled on the vehicle through the Electronic Braking System (EBS) in a similar fashion to that shown in Figure 6. Additional braking torque is present on the vehicle, although to a much lesser extent, through the engine friction torque and alternators which will produce small rates of deceleration and generate energy for use in Page 8 of 11 auxiliary systems. Although smaller in magnitude, the hybrid system must take this torque into account to prevent stalling or jerking of the vehicle. The EBS manages the braking torque requests to the main braking systems.

The regenerative braking opportunities on the HEV vehicles are maximised by, subject to the safe operating limits of the vehicle, requesting $100 \%$ of the maximum torque available where possible to recover braking energy. Under normal operational conditions, the logic prioritises the MGUs to maximise the recuperation of energy through regenerative braking. The hydraulic retarder has second priority and the foundation brakes are only requested to provide the remainder of the braking force, while complying with all relevant legislation for brake operation. An example of this is shown in the test results in Figure 17 where the vehicle draws $100 \%$ of the maximum available torque from the MGUs to assist during the braking event to maximise regen (retarder/foundation brake requests not shown).

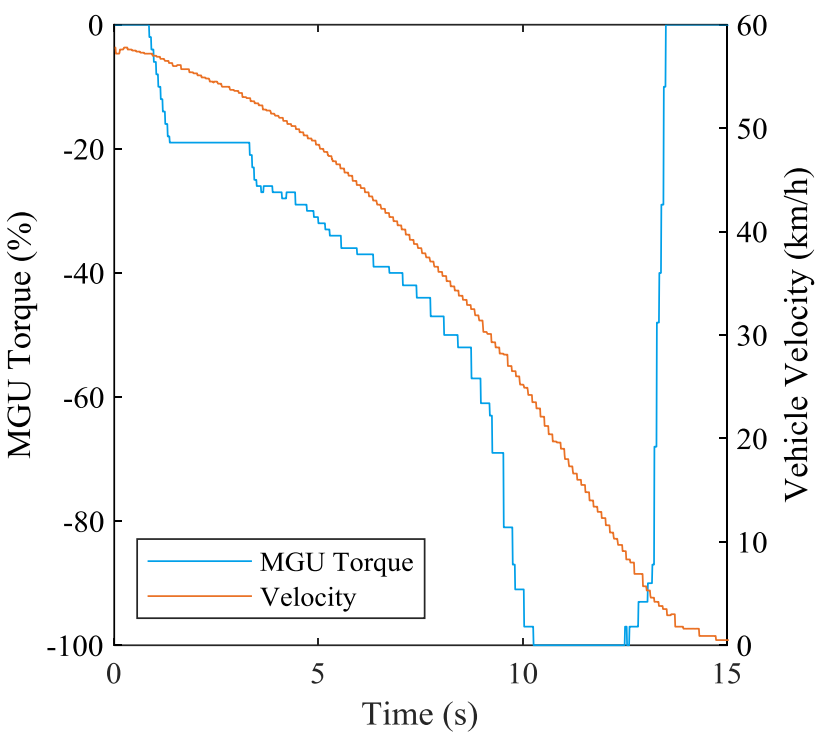

Figure 17 - MGU torque during deceleration

Regenerative braking during accelerator pedal lift-off is also incorporated on this vehicle to increase the amount of energy recuperated. It was found during testing that the setting of the torque level during lift-off resulted in variable feedback from drivers on the test vehicles and requires careful tuning to provide a balance. Ultimately, the torque setting was maximised to improve the energy recuperation but not increased to the point where it interfered with other systems on the vehicle or the driveability of the vehicle itself.

\section{Vehicle Testing and Accreditation Process}

After initial modelling and simulation had been completed, a period of vehicle development was conducted on prototype vehicles at the Millbrook Proving Ground in Bedford, England to demonstrate the ability of the new vehicle architecture to achieve significant emissions and fuel economy savings. In order to be eligible for additional grant funding in the UK under the Department for Transport/Office for Low Emissions Vehicles Low Emission Bus (LEB) scheme, a Low Emission Bus Certificate, issued by the Low Carbon Vehicle Partnership, is required. The data used in this certification process is derived from independently witnessed 
emissions tests and calculation of Well-to-Wheel (WTW) Greenhouse Gas (GHG) emissions savings. The testing is split into two main components:

1. Whole Vehicle Testing on a chassis dynamometer, where the vehicle emissions are measured on the LUB drive cycle

2. WTW Greenhouse Gas Emissions calculation, derived from the tank to wheel (TTW) emissions from the whole vehicle test and a Well to Tank (WTT) emission factor applicable to the fuel used in the bus.

The results are combined to produce overall WTW number of grams of equivalent carbon dioxide per kilometre. Under testing, the vehicle weight is determined through the unladen kerb weight and assuming a loading of $50 \%$ seated passenger capacity (nominal $68 \mathrm{~kg}$ per passenger), in line with testing guidelines. The chassis dynamometer is setup to replicate measured coast-down forces obtained from actual road load data.

Table 3. Global Warming Potential relative to $\mathrm{CO}_{2}$ (100 year) [12]

\begin{tabular}{lccc}
\hline & $\begin{array}{c}\text { Carbon } \\
\text { Dioxide }\left(\mathrm{CO}_{2}\right)\end{array}$ & $\begin{array}{c}\text { Methane } \\
\left(\mathrm{CH}_{4}\right)\end{array}$ & $\begin{array}{c}\text { Nitrous Oxide } \\
\left(\mathbf{N}_{\mathbf{2}} \mathbf{O}\right)\end{array}$ \\
\hline $\begin{array}{l}\text { Global Warming } \\
\text { Potential (GWP) }\end{array}$ & 1 & 25 & 298 \\
\hline
\end{tabular}

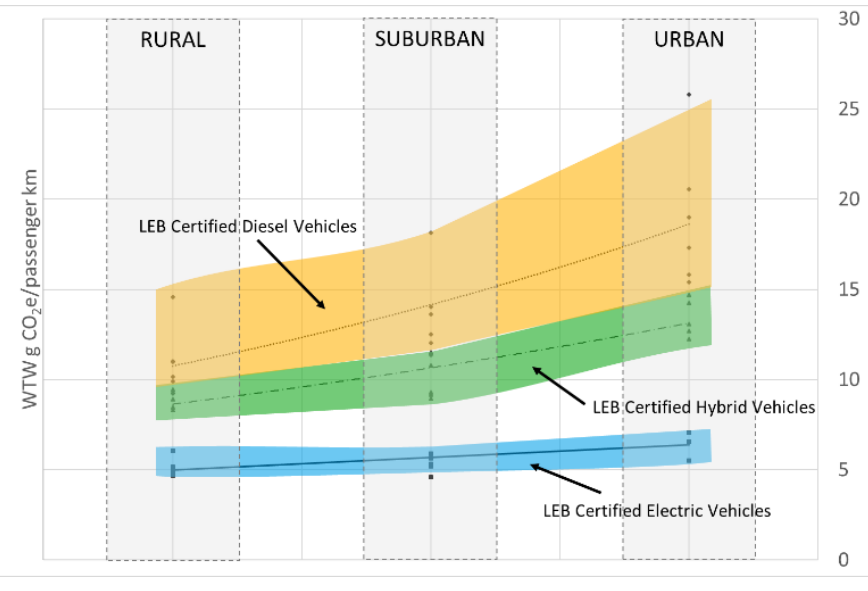

Figure 18-Certified Diesel, Hybrid, Electric buses in the UK [13]

Based on the Low Emissions Bus certification scheme, a Euro VI diesel bus is assumed to have a WTW greenhouse gas emissions (in $\mathrm{g} / \mathrm{km})$ of $W T W G H G(\mathrm{~g} / \mathrm{km})=9.42 \times$ Total Passenger Capacity + 480. For classification as a Low Emissions Bus, the vehicle must have a WTW GHG value of $15 \%$ less than this, based on WTW GHG $(\mathrm{g} / \mathrm{km})=8.00 \times$ Total Passenger Capacity +408 . The GHGs are defined as a $\mathrm{CO}_{2}$ equivalent $\left(\mathrm{CO}_{2} \mathrm{e}\right)$, where the Global Warming Potential (GWP) of each of the pollutants is converted into grams of $\mathrm{CO}_{2}$ based on IPCC assessment data (Table 3) [12]. The WTW GHG emissions are calculated through addition of WTT emissions and measured tailpipe or TTW emissions. For the WTT efficiency, a pump diesel (average biofuel blend) conversion factor of 554.32 $\mathrm{gCO}_{2} \mathrm{e} /$ Litre (Net CV), $15.42 \mathrm{gCO}_{2} \mathrm{e} / \mathrm{MJ}$ (Net CV) is assumed, based on the DECC reported factors [12].

Based on currently certified Low Emission Buses in the UK, the clear benefits of hybridisation in the bus sector can be seen in Figure 18

Page 9 of 11 above. UK LEB certified hybrid technologies consistently reduce the WTW GHG profiles across all styles of driving compared against similarly certified diesel vehicles, clearly bridging the gap between the diesel and fully electric comparative vehicles. In many instances, the benefits of the hybrid vehicles become more pronounced in the inner-city driving zones (urban), where average reductions in WTW g $\mathrm{CO} 2 \mathrm{e} /$ passenger $\mathrm{km}$ of over $28 \%$ against the average LEB certified diesel vehicle are achieved. This equates to WTW g CO2e/passenger $\mathrm{km}$ savings of $41 \%$ of those achievable through conversion to fully electric vehicle technology.

Table 4. Certified Well-to-Wheel Greenhouse Gas CO2 Equivalent Emissions on LUB drive cycle (Streetlite) [13]

\begin{tabular}{lllll}
\hline Test Phase & $\begin{array}{l}\text { Fuel } \\
\text { Energy } \\
\text { MJ/km }\end{array}$ & $\begin{array}{l}\text { Fuel WTT } \\
\text { GHG } \\
\text { Emissions } \\
\text { gCO2e/km }\end{array}$ & $\begin{array}{l}\text { Measured } \\
\text { TTW GHG } \\
\text { Emissions } \\
\text { gCO2e/km }\end{array}$ & $\begin{array}{l}\text { Total WTW } \\
\text { GHG } \\
\text { Emissions } \\
\text { gCO2e/km }\end{array}$ \\
\hline Rural & 7.40 & 114.1 & 556.2 & 670.3 \\
\hline Semi-Urban & 7.89 & 121.6 & 595.4 & 717.0 \\
\hline Urban & 11.65 & 179.6 & 876.1 & 1055.6 \\
\hline LUB Average & 8.24 & 127.0 & 620.3 & 747.3 \\
\hline $\begin{array}{l}\text { Euro VI Diesel } \\
\text { Baseline }\end{array}$ & & & & $\begin{array}{l}\mathbf{- 3 8 2 . 6 ( 3 4 \%} \\
\text { reduction) }\end{array}$ \\
\hline
\end{tabular}

Table 5. Certified Well-to-Wheel Greenhouse Gas CO2 Equivalent Emissions on LUB drive cycle (StreetDeck) [13]

\begin{tabular}{lllll}
\hline Test Phase & $\begin{array}{l}\text { Fuel } \\
\text { Energy } \\
\text { MJ/km }\end{array}$ & $\begin{array}{l}\text { Fuel WTT } \\
\text { GHG } \\
\text { Emissions } \\
\text { gCO2e/km }\end{array}$ & $\begin{array}{l}\text { Measured } \\
\text { TTW GHG } \\
\text { Emissions } \\
\text { gCO2e/km }\end{array}$ & $\begin{array}{l}\text { Total } \\
\text { WTW } \\
\text { GHG } \\
\text { Emissions } \\
\text { gCO2e/km }\end{array}$ \\
\hline Rural & 8.87 & 136.8 & 668.7 & 805.4 \\
\hline Semi-Urban & 9.66 & 149.0 & 733.4 & 882.3 \\
\hline Urban & 13.57 & 209.3 & 1020.8 & 1230.1 \\
\hline LUB Average & 9.88 & 152.4 & 746.6 & 899.0 \\
\hline $\begin{array}{l}\text { Euro VI Diesel } \\
\text { Baseline }\end{array}$ & & & & $\begin{array}{l}\mathbf{- 4 7 5 . 9} \\
\mathbf{3 5 \%} \\
\text { reduction) }\end{array}$
\end{tabular}

Focusing on the Wrightbus Streetlite HEV (Table 4) and the Wrightbus Streetdeck HEV (Table 5) vehicles, both vehicles demonstrated consistently strong performance in vehicle testing, achieving $34 \%$ and $35 \%$ reductions in total WTW GHG Emissions $\left(\mathrm{gCO}_{2} \mathrm{e} / \mathrm{km}\right)$ compared to the Euro VI diesel baseline. 


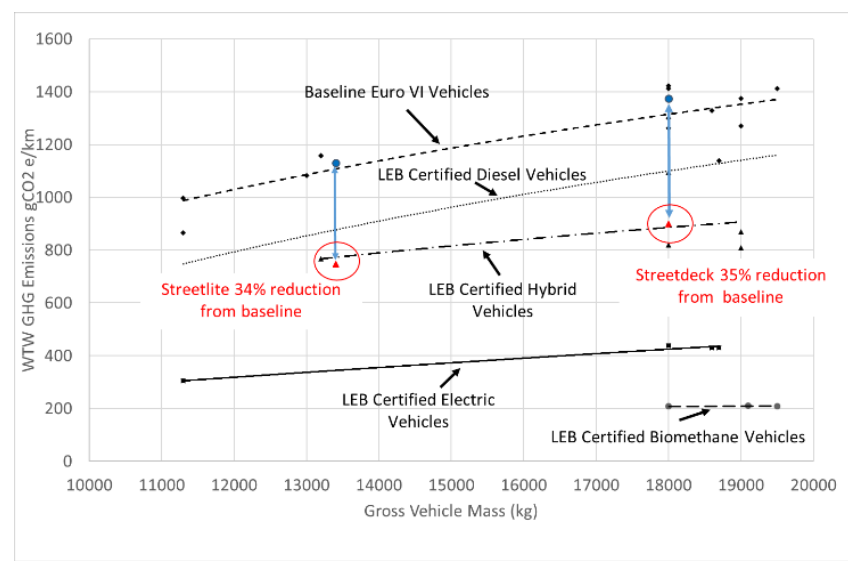

\section{Figure 19 - Relationship between Gross Vehicle Mass and WTW GHG for Low Emission Vehicles}

What is of particular interest is the effectiveness of the hybridisation in reducing the WTW $\mathrm{g} \mathrm{CO} 2 \mathrm{e} / \mathrm{km}$ achievable for the higher mass vehicles. Considering Figure 20, on a per passenger basis, the hybrid technologies are achieving up to $55 \%$ of the WTW g CO2e/ km savings achievable from the average fully electric vehicle in the same mass range, with the hybrid Streetdeck vehicle performing slightly better than these average performance factors (57\%). When balanced against the cost of acquisition, this presents an attractive alternative technology to full electric vehicles.

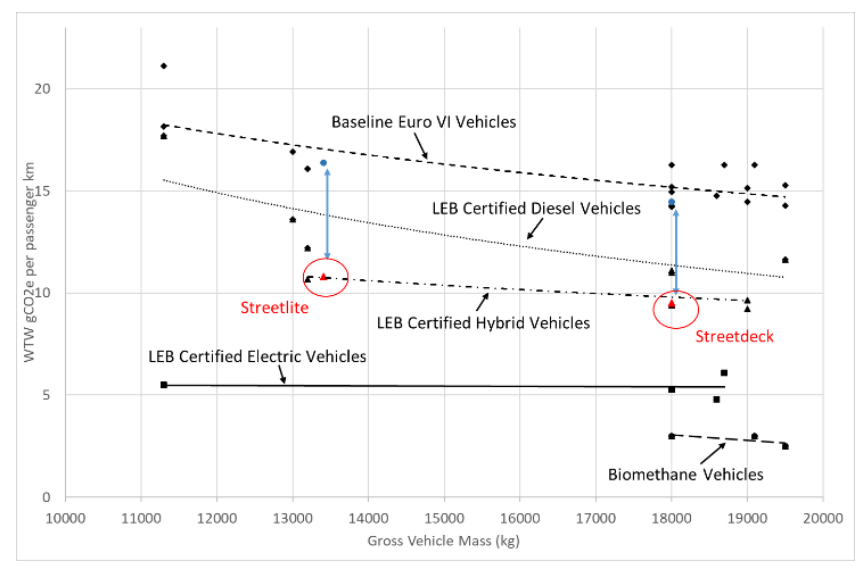

Figure 20-Relationship between Gross Vehicle Mass and WTW GHG per passenger km for Low Emission Vehicles

Figure 19 and Figure 20 further explore the relationship between the vehicle mass and the achievable WTW g CO2e/ km and WTW g $\mathrm{CO} 2 \mathrm{e} /$ passenger $\mathrm{km}$. In both instances, both the next generation hybrid vehicles developed through this program are performing in line with average performance of all hybrid vehicles currently certified for Low Emission Bus status in the UK, demonstrating both the scalability of the performance of the hybrid powertrain to the higher vehicle mass range. It also confirms the findings of several theoretical studies which have hypothesized that the well-to-wheel savings achievable from the hybrid electric vehicle powertrains are likely to provide the best solution in the short to medium term [14, 15]. These achievements have been made without the need for additional infrastructure, without the range or terrain issues associated with other technologies, and at a comparatively lower cost than other alternative powertrains.

\section{Conclusions}

The current programme has successfully demonstrated the viability of converting a micro-hybrid bus configuration (the Wrightbus MicroHybrid v3) to a next generation parallel hybrid architecture, the single deck Streetlite HEV and double deck Streetdeck HEV. Furthermore, the underlying powertrain and control strategy are scalable between single deck and double deck vehicle variants, both achieving comparable driving performance to their baseline comparators.

Unlike the $48 \mathrm{~V}$ equipment popular in the automotive and truck sector, the $96 \mathrm{~V}$ system is required to achieve the desirable fuel efficiency and emissions savings in the bus industry. The implemented control strategy developed for a $\mathrm{P} 3$ post-transmission parallel vehicle topology successfully balances torque demand under acceleration events to maximise the usage of the stored electrical energy, while the regenerative braking was prioritised when possible to maximise energy recuperation while working within a charge sustaining strategy.

Both Streetlite HEV (69 passenger capacity) and Streetdeck HEV (95 passenger capacity) hybrid vehicles have been issued with Low Emission Bus certificates from the Low Carbon Vehicle Partnership, demonstrating at least a $15 \%$ GHG WTW saving compared with a Euro VI diesel bus of the equivalent passenger capacity across the new LUB cycle. The Streetlite vehicle achieved 34\% reduction in Well-To-Wheel greenhouse gas savings, with $10.8 \mathrm{~g} \mathrm{CO} 2 \mathrm{e} /$ passenger $\mathrm{km}$, with even further improvements in the double deck variant, with 35\% reduction in Well-To-Wheel greenhouse gas savings, with $9.5 \mathrm{~g} \mathrm{CO} 2 \mathrm{e} /$ passenger $\mathrm{km}$.

\section{References}

1. Mahmoud, M., Garnett, R., Ferguson, M. and Kanaroglou., "Electric buses: A review of alternative powertrains," Renewable and Sustainable Energy Reviews, Volume 62, September 2016, Pages 673-684, doi: 10.1016/j.rser.2016.05.019

2. UK Automotive Council, "Bus Technology Roadmap," www.automotivecouncil.co.uk, accessed October 2018

3. Transport for London, " Ultra Low Emission Zone," https://tfl.gov.uk/modes/driving/ultra-low-emission-zone, accessed January 2019

4. Sadler Consultants Ltd, " Urban Access Regualations in Europe," http://urbanaccessregulations.eu/, accessed January 2019

5. The Wall Street Journal, "China Has 487 Electric-Car Makers, and Local Governments Are Clamoring for More," https://www.wsj.com/articles/china-has-487-electric-carmakers-and-local-governments-are-clamoring-for-more1531992601, 19 July 2018, accessed 2019

6. Hu, B., Chen, C., Zhan, Z., Su, X., Hu, T., Zheng, G. and Yang, $\mathrm{Z}$., "Progress and recent trends in $48 \mathrm{~V}$ hybridisation and eboosting technology on passenger vehicles - a review," Proceedings of the Institution of Mechanical Engineers, Part D: Journal of Automobile Engineering, Volume 232, Issue 11, 2018, doi: 10.1177/0954407017729950

7. Sabri, M., Danapalasingam, K. and Rahmat, M. "A review on hybrid electric vehicles architecture and energy management strategies" Rewnable and Sustainable Energy Reviews, Volume 53, January 2016, Pages 1433-1442, doi: 10.1016/j.rser.2015.09.036 
8. Enang, W. and Bannister, C. "Modelling and control of hybrid electric vehicles (A comprehensive review)" Renewable and Sustainable Energy Reviews 74, 2017, Pages 2012-1239, doi: 10.1016/j.rser.2017.01.075

9. Huang, Y., Wang, H., Khajepour, A., Li, B., Ji, J., Zhao, K. and $\mathrm{Hu}, \mathrm{C}$. "A review of power management strategies and component sizing methods for hybrid vehicles" Renewable and Sustainable Energy Reviews 96, 2018, Page 132-144, doi:/ 10.1016/j.rser.2018.07.020

10. Stevens, G., Murtagh, M., Kee, R., Early, J. and Best, R. "Development of a Vehicle Model Architecture to Improve Modeling Flexibility" SAE International Journal of Engines. 2017 Mar 28;10(3). 2017-01-1138. Available from, DOI: 10.4271/2017-01-1138

11. LowCVP, "Testing and Accrediation Procedures," https://www.lowcvp.org.uk/Hubs/leb/TestingandAccreditation/T estingAccreditationProcedures.htm, accessed October 2018.

12. Department for Business, Energy and Industrial Strategy "UK Greenhouse Gas Inventory"

https://www.gov.uk/government/publications/greenhouse-gasreporting-conversion-factors-2016, accessed October 2018

13. Low Carbon Vehicle Partnership "LEB Certificates" https://www.lowcvp.org.uk/Hubs/leb/LEBCertificates.htm accessed October 2018

14. Correa, G., Munoz, P., Falaguerra, T. and Rodriguez, C.R. "Performance comparison of conventional, hybrid, hydrogen and electric urban buses using well to wheel analysis" Energy 141, December 2017, Pages 537-549, doi:/ 10.1016/j.energy.2017.09.066

15. Millo, F., Rolando, L., Fuso, R. and Zhao, J. "Development of a new hybrid bus for urban public transportation" Applied Energy 157, 2015, Pages 583-594

\section{Contact}

Sir William Wright Technology Centre, 50 Malone Road, Queen's University Belfast, Belfast, BT9 5BS, United Kingdom

email: wtech@qub.ac.uk

\section{Acknowledgments}

This work was supported by the Northern Ireland Department for the Economy (DfE), Innovate UK and Wrightbus. 